\section{Commentary: A tale of two eities surgeons}

\section{Eugene H. Blackstone, MD}

Nearly 40 years ago, Dr John Kirklin reviewed results of coronary artery bypass grafting $(\mathrm{CABG})$ at a hospital whose administrators were alarmed that public reporting was imminent. They believed their CABG mortality was too high, but their 2 surgeons claimed they operated on the "sickest of the sick." We applied our institutional CABG hospital mortality model to their data, finding that indeed they operated on high-risk patients (Figure 1). Mortality was "as expected" for Surgeon A, but twice that expected for Surgeon B. Reassessed a year later, Surgeon A undertook fewer high-risk operations and mortality decreased but remained "as expected." Case mix remained unchanged for Surgeon B: his mortality remained high. During year 3, neither surgeon undertook high-risk operations. Mortality for the low-risk patients of Surgeon A was half that expected-his risk-adjusted results improved. In contrast, Surgeon B's mortality, although substantially reduced, remained 3 times greater than expected for low-risk cases.

This tale of 2 surgeons illustrates 2 responses to the specter of public reporting. One is to divert high-risk cases to other centers or not perform needed surgery (risk aversion). ${ }^{1}$ Responsible diversion of complex cases to centers better equipped to manage them is in the best interest of patients and may apparently improve results, but observed low mortality can mask higher-thanexpected mortality among low-risk patients.

From the Department of Thoracic and Cardiovascular Surgery, Sydell and Arnold Miller Family Heart, Vascular, and Thoracic Institute, Cleveland Clinic, Cleveland, Ohio.

Disclosures: Dr Blackstone is a founding member of the American Association for Thoracic Surgery Quality Gateway.

The Journal policy requires editors and reviewers to disclose conflicts of interest and to decline handling or reviewing manuscripts for which they may have a conflict of interest. The editors and reviewers of this article have no conflicts of interest.

Received for publication June 25, 2021; revisions received June 25, 2021; accepted for publication June 29, 2021; available ahead of print Aug 14, 2021.

Address for reprints: Eugene H. Blackstone, MD, Department of Thoracic and Cardiovascular Surgery, Sydell and Arnold Miller Family Heart, Vascular, and Thoracic Institute, Cleveland Clinic, 9500 Euclid Ave, Desk JJ-40, Cleveland, OH 44195 (E-mail: blackse@ ccf.org).

JTCVS Open 2021;7:272-3

2666-2736

Copyright (c) 2021 The Author(s). Published by Elsevier Inc. on behalf of The American Association for Thoracic Surgery. This is an open access article under the CC BY-NC-ND license (http://creativecommons.org/licenses/by-nc-nd/4.0/).

https://doi.org/10.1016/j.xjon.2021.06.020

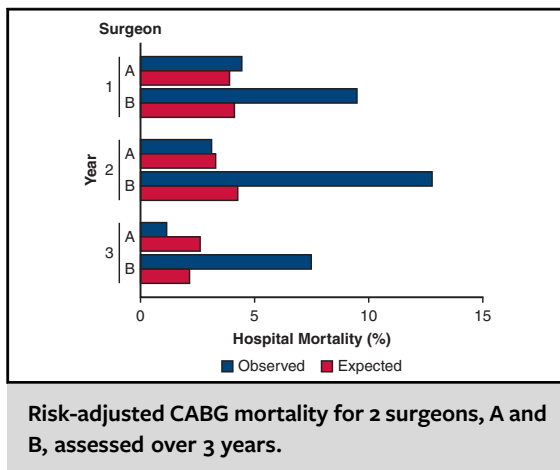

CENTRAL MESSAGE

Whether causal or not, public reporting has been associated with lowered mortality after cardiac surgery.

The second response, as for Surgeon A, is to improve. In the New York State Cardiac Advisory Committee's deliberations on public reporting, ${ }^{2}$ its chair, Dr Kirklin, asked, "Is the purpose of public reporting to identify and eliminate bad apples, or is it to improve the results of heart surgery in the State of New York?" Public reporting, done responsibly and understandably, should stimulate serious, tough, vigilant processes of improving teamwork, infrastructure, and skill so that appropriate patients can undergo surgery at low risk.

Grant and colleagues ${ }^{3}$ report reduction for all procedure types in hospital mortality across the United Kingdom despite evidence that risk profile increased, indicating that in a climate of public transparency, early risk of cardiac surgery can be mitigated. Rapid actionable feedback of national and institutional results to the clinical team, coupled with cooperative sharing of best practices, ${ }^{4}$ is needed to reach the next level of quality improvement, not only in the United Kingdom, but everywhere. ${ }^{5}$

Westaby and colleagues ${ }^{6,7}$ and others ${ }^{8}$ are concerned about unintended consequences of public reporting. They cite statistics showing few UK trainees becoming cardiac surgeons, particularly since the widely publicized Bristol Children's Heart scandal. ${ }^{9}$ They rightly point out that in a specialty that requires a large, multidisciplinary team that relies on well-functioning infrastructure, it is wrong to 


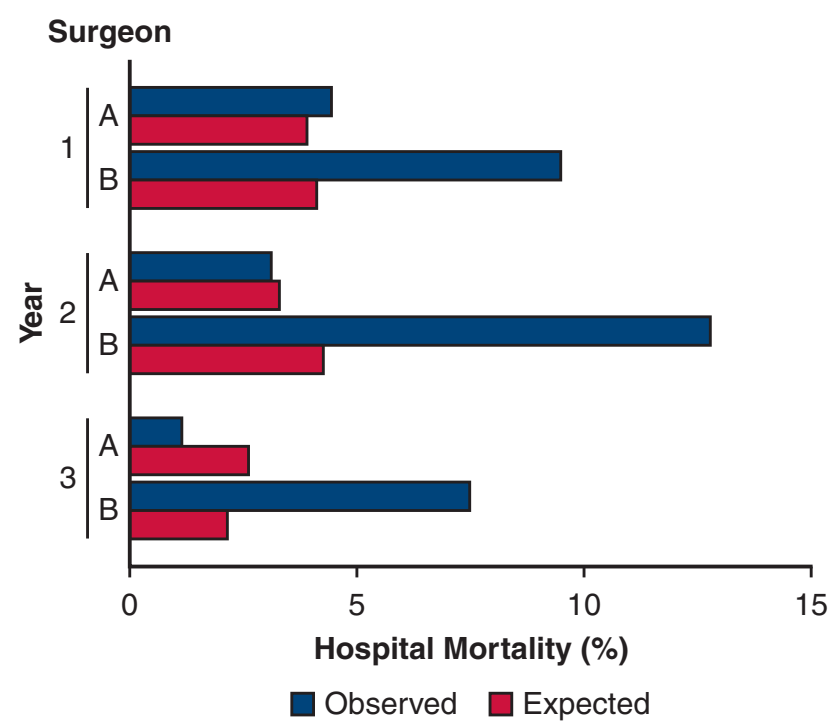

FIGURE 1. Observed and risk-adjusted expected mortality for coronary artery bypass grafting performed by 2 surgeons, monitored over a 3-year period, nearly 40 years ago. During year 1 , Surgeon A had a mortality about as expected, but Surgeon B had a mortality more than twice that expected. During year 2, observed mortality for Surgeon A was lower, but equivalent to expected - case mix had changed by patient diversion or risk aversion. Case mix for Surgeon B remained unchanged as did higher-thanexpected risk-adjusted mortality. During year 3, case mix was reduced to low-risk patients, but now Surgeon A's mortality for these low-risk patients was half that expected, indicating quality improvement. Surgeon B's case mix was also dramatically reduced to low-risk patients, and his observed mortality was only about half of that during year 2. But that low mortality was more than 3 times greater than expected for these low-risk patients. attribute deaths to just 1 of those team members; that is, the surgeon. ${ }^{7}$ On occasion, there are surgeons like Surgeon B, or excellent surgeons who are unfairly maligned. But the result of transparent public reporting in the United Kingdom and beyond seems to be associated with a benefit to patients, whether directly causal or not. ${ }^{10}$

\section{References}

1. Omoigui NA, Miller DP, Brown KJ, Annan K, Cosgrove D III, Lytle B, et al. Outmigration for coronary bypass surgery in an era of public dissemination of clinical outcomes. Circulation. 1996;93:27-33.

2. Zinman D. Heart surgeons rated: state reveals patient-morality records. New York Newsday. December 18, 1991;3.

3. Grant SW, Kendall S, Goodwin AT, Cooper G, Trivedi U, Page R, et al. Trends and outcomes for cardiac surgery in the United Kingdom from 2002 to 2016. J Thorac Cardiovasc Surg Open. 2021;7:259-69.

4. O'Connor GT. Physician leadership in cardiac outcomes reporting. Ann Thorac Surg. 2000;70:693-4

5. Blackstone EH, Swain J, McCardle K, Adams DH, Governance Committee, American Association for Thoracic Surgery Quality Assessment Program. A comprehensive American Association for Thoracic Surgery quality program for the 21st century. J Thorac Cardiovasc Surg. 2019;158:1120-6.

6. Westaby S, Baig K, Pepper J. Publishing SSMD: the risks outweigh the benefits. Bull R Coll Surg Engl. 2015;97:155-9.

7. Westaby S, Baig K, De Silva R, Unsworth-White J, Pepper J. Recruitment to UK cardiothoracic surgery in the era of public outcome reporting. Eur J Cardiothorac Surg. 2015;47:679-83.

8. Chassin MR, Hannan EL, DeBuono BA. Benefits and hazards of reporting medical outcomes publicly. N Engl J Med. 1996;334:394-8.

9. Aylin P, Alves B, Best N, Cook A, Elliott P, Evans SJ, et al. Comparison of UK paediatric cardiac surgical performance by analysis of routinely collected data 1984-96: was Bristol an outlier? Lancet. 2001;358:181-7.

10. Peterson ED, DeLong ER, Jollis JG, Muhlbaier LH, Mark DB. The effects of New York's bypass surgery provider profiling on access to care and patient outcomes in the elderly. J Am Coll Cardiol. 1998;32:993-9. 